\title{
Effect of testosterone and cortisol administration on the reproductive tract of male Antechinus stuartii (Marsupialia)
}

\author{
B. M. McAllan \\ Department of Physiology, University of New England, Armidale, NSW 2351, Australia
}

\begin{abstract}
The life history of Antechinus stuartii, a marsupial, is highly synchronized and culminates in a brief mating period that is followed by complete male mortality. The accessory reproductive tracts of male $A$. stuartii enlarge in association with testosterone and cortisol hormone concentrations, but this appears to be unrelated to the spermatogenic cycle. The present study examined the effects of testosterone and cortisol on the male reproductive tract. Four groups of adult males from May (when plasma testosterone and cortisol concentrations are low) were given depot injections of testosterone esters or synthetic cortisol in doses that mimic concentrations found in males in the breeding period (August). Males were given either saline, testosterone only, cortisol only, or testosterone plus cortisol. Experimental groups did not differ in the seminiferous tubule morphology. However, the cells from the caudal end of the epididymides of both testosterone groups were considerably hypertrophied compared with males treated with saline or cortisol only. Testosterone treatment significantly increased prostate and bulbourethral gland mass, although addition of cortisol to the testosterone administration diminished this effect. The morphology of the accessory reproductive tract of males treated with either saline or cortisol only was similar to that of untreated males at the same time of year, and the morphology of the accessory reproductive tract of males treated with testosterone plus cortisol was similar to that of untreated males in the breeding season. Like some other marsupials, the spermatogenic cycle in $A$. stuartii is apparently not correlated with androgen activity, while the accessory reproductive tract is affected by androgens.
\end{abstract}

\section{Introduction}

The highly synchronous life cycle of the marsupial Antechinus stuartii includes post-mating mortality of all males after the brief (1-2 weeks) mating period (Woolley, 1966; McDonald et al., 1981). The synchronous life cycle includes pronounced endocrinological changes. In males, plasma testosterone increases from basal concentrations in June, when spermatogenesis ceases, to an eightfold peak in August (Bradley et al., 1980; Kerr and Hedger, 1983). Plasma cortisol concentrations double from July to August (Bradley et al., 1980). Moreover, there are pronounced synchronous seasonal changes in the reproductive tract of male $A$. stuartii, including a spermatogenic cycle which is the same for all males at each time of year, and with few associations of germ cells compared with other mammals (Kerr and Hedger, 1983). The Leydig cells differentiate between February and May, continuing to enlarge and proliferate throughout the year (Kerr and Hedger, 1983; McAllan et al., 1997a). Initial specialization of the epididymis occurs in May and epithelial height and cell volumes increase significantly through the year, with differences between the caput and caudal end becoming more pronounced as the year progresses (Taggart and Temple-Smith, 1992; McAllan et al.,

Received 23 May 1997 1997a). The later differentiation of the epididymis, observed in a study on the seasonal changes in morphology (McAllan et al., 1997a), suggests that the epididymis is stimulated by the actions of androgens, as the changes parallel the increase in androgens observed in other studies (Moore, 1974; Bradley et al., 1980).

The plasma concentrations of androgens found in other studies on A. stuartii also correspond to the changes seen in the accessory reproductive tract. The prostate and Cowper's glands are differentiated in July (McAllan et al., 1997a), after spermatogenesis has ceased and androgens have reached their peak plasma concentration (Bradley et al., 1980; Kerr and Hedger, 1983). Cellular differentiation and secretory activity increase from July through to August, and maximal activity is observed during the mating season (McAllan et al., 1997a). The known correlation between plasma androgen concentrations and the increase in prostate and Cowper's gland masses (Woolley, 1966; Bradley et al., 1980) is also correlated with the changes in microanatomy (McAllan et al,, 1997a).

Studies on other marsupials suggest that testosterone has a marked effect on accessory gland growth, but that this can be independent of spermatogenic activity (Cook et al., 1978; Gemmell et al., 1986; Jones et al., 1988; Curlewis, 1991). In male $A$. stuartii, spermatogenesis has ceased, and the germinal epithelium has collapsed, before plasma testosterone 
concentrations increase and the breeding period has begun. However, the cessation of spermatogenic activity is not associated with a collapse in the interstitium of the testes, which is maintained (Woolley, 1966; Taggart et al., 1993; McAllan et al., 1997a). The uncoupling of these events suggests that, first, testosterone concentration has little effect on spermatogenic activity, and second, that testosterone is important for accessory gland development, independent of the spermatogenic cycle.

The present study was undertaken to examine the effects of testosterone and cortisol administration on the reproductive tract in male $A$. stuartii and to determine whether spermatogenesis and accessory gland development are controlled separately, as suggested by a seasonal study (McAllan et al., 1997a), and by other studies on Antechinus (Woolley, 1966; Kerr and Hedger, 1983; Wilson and Bourne, 1984; Taggart and Temple-Smith, 1989). In an attempt to resolve this, changes in the reproductive tract were investigated after testosterone and cortisol administration in May, when endogenous hormone concentrations are known to be low (Moore, 1974; Bradley et al., 1980).

\section{Materials and Methods}

\section{Animals}

Twenty-four male A. stuartii were captured in late April from the New England Tablelands, NSW, Australia. At that time, wild $A$. stuartii are of adult body mass, although they are sexually immature. Permission for the study was granted by the New South Wales National Parks and Wildlife Service, and the Animal Ethics Committee of the University of New England.

A. stuartii were caged individually in plastic cages $30 \mathrm{~cm} \times 60 \mathrm{~cm} \times 20 \mathrm{~cm}$ with Fibresorb organic animal litter (Australian Fibresorb Pty Ltd, Melbourne) fitted with a nest box containing nesting material. Water was available ad libitum and at least $20 \mathrm{~g}$ of Whiskas tinned cat food (Uncle Ben's of Australia Ltd, Sydney) was provided just before dusk each day. The food was a mixture of beef, chicken, mutton, and rabbit meat, gel, flavour, food colouring, minerals and vitamins and contained $9.0 \%$ crude protein, $6.0 \%$ crude fat, $0.4 \%$ naturally occurring salt, and $1.0 \%$ crude fibre. Animals were housed under natural photoperiod at $22 \pm 3^{\circ} \mathrm{C}$. Body mass was measured on capture and at the end of the experiment.

\section{Hormone injections}

After a week of acclimation to captivity, the animals were given an i.m. injection (range of total volume, depending on body mass, $0.04-0.08 \mathrm{ml})$ of saline $(n=6)$, testosterone (150 $\mathrm{mg} \mathrm{kg}^{-1}$ Durateston, injection of mixed testosterone esters, Intervet, Boxmeer; $n=6)$, cortisol $\left(75 \mathrm{mg} \mathrm{kg}^{-1}\right.$ Depredil, injection of methylprednisolone acetate, Ilium, Sydney; $n=6$ ) or testosterone plus cortisol ( $150 \mathrm{mg} \mathrm{kg}^{-1}$ Durateston, $75 \mathrm{mg} \mathrm{kg}^{-1}$, Depredil; $n=6$ ). Methylprednisolone acetate was used because it is a potent glucocorticoid, with little mineralocorticoid action, similar to cortisol (Tepperman and Tepperman, 1987). Depredil is a depot form of methylpred- nisolone acetate, acting over a 2 week period, its mineralocorticoid action is 0.8 times the potency of cortisol and its immunosuppressive action is five times the potency of cortisol (Tepperman and Tepperman, 1987). However, the mineralocorticoid activity was of special interest for another study (McAllan et al, 1997b) and was mimicked most closely by Depredil of all other available synthetic corticosteroids (Tepperman and Tepperman, 1987). Depredil was also chosen for animal ethics considerations, following the guidelines of the Animal Ethics and Care Committee, University of New England. In this study 'cortisol administration' refers to the administration of Depredil. The cortisol dosages were based on the data of Bradley et al. (1975), to give an estimated daily release of $5 \mathrm{mg} \mathrm{kg}^{-1} \mathrm{day}^{-1}$. The testosterone dosages were based on data from McDonald et al. (1981) and Bradley et al. (1980), to give an estimated dose of $10 \mathrm{mg} \mathrm{kg}^{-1}$ day ${ }^{-1}$. A second injection of the same concentration was given 15 days later. Between 5 and 6 weeks after the initial hormone injections, the animals were killed. Two individuals treated with cortisol died before the experiment was completed, but their reproductive tracts were analysed, and one animal treated with testosterone plus cortisol was killed before 5-6 weeks because of a deterioration of its condition. Another animal treated with testosterone plus cortisol escaped and was not recaptured.

\section{Histology}

All animals were given an overdose of Nembutal pentobarbitone sodium $\left(60 \mathrm{mg} \mathrm{ml}^{-1}\right.$, Boehringer, Ingelheim), based on the rate for anaesthesia for dogs $\left(2.3 \mathrm{ml}(5 \mathrm{~kg})^{-1}\right)$ 5-6 weeks after the initial injection. When the animals were deeply anaesthetized, they were quickly decapitated and blood was collected for another study. Testes, Cowper's glands and prostate were weighed before placement in 10\% neutral buffered formalin. After fixation, samples were dehydrated and embedded in paraffin wax and were sectioned serially at $6 \mu \mathrm{m}$. Sections were stained for general observation with haematoxylin and eosin or Masson's trichrome (Drury and Wallington, 1980). In addition, the accessory reproductive tract was stained with Periodic acid-Schiff (PAS) with either Alcian blue $\mathrm{pH} 1.0$ or Alcian blue pH 2.5 (Drury and Wallington, 1980).

\section{Morphometry}

The testes, bulbourethral glands and prostates of all animals were weighed after death. The scrotal sacs were dissected away from the testes before weighing the testes. Definitions for the bulbourethral glands are according to those of McAllan $e t$ al. (1997a). The external scrotal width was measured on capture and used as an external index of male maturity (Woolley, 1966). Measurements were made at $90^{\circ}$ to each other using vernier calipers to eliminate any individual scrotal irregularities. The values were then averaged (McAllan et al., 1991).

Epithelial cell heights of the caudal and caput epididymides were measured and epithelial cell volumes were estimated using the nucleator method and using the formula for estimating the volume of a cylinder $\left(\pi \mathrm{r}^{2} h\right.$; Gundersen et al., 1988a). Sample sizes of each variable for each individual were 
determined by ensuring that the coefficient of error was $P<0.05$ (Gundersen et al., 1988b).

\section{Statistical methods}

Testes mass, prostate mass and bulbourethral gland mass were analysed by two-way ANOVA for cortisol and testosterone, followed by pairwise Fisher's PLSD tests (Zar, 1984; Haycock et al., 1992). Mass data were also analysed as a percentage of body mass. Percentage data were arcsine transformed before analysis; however, original percentage values are presented in the tables ( $\mathrm{Zar}, 1984$ ). The differences between scrotal width at capture and at death were assessed by two-way ANOVA for cortisol and testosterone treatments. Epididymal cell heights and volumes were analysed by twoway ANOVA for cortisol and testosterone, followed by pairwise Fisher's PLSD tests (Zar, 1984; Haycock et al., 1992).

\section{Results}

\section{External morphology}

At the end of the experiment, the appearance of the external genitalia of $A$. stuartii treated with saline was similar to that seen in other males from early June in other studies (Woolley, 1966; McAllan et al., 1991). The scrotum was retractile and unpigmented, and the sternal gland was evident in only one individual. No bulbourethral glands were observed on palpation of the urogenital region. In contrast, all males treated with testosterone only had a large and secretory sternal gland. The scrotum was losing fur in two individuals, darkly pigmented in another individual, and was retractile in all but one individual. All males treated with testosterone only had a mature erectile penis and palpable bulbourethral glands, evident within 10 days of hormone injection. By the end of the experiment, the bulbourethral glands were large and were observed as two large masses, one on each side of the urogenital sinus. In males treated with cortisol only, some minor changes were observed in some individuals. The sternal gland was observed in two individuals and an immature penis was seen in one of these males. The scrotal sac was not retractile and was losing fur in some individuals and was black under the fur in another of these individuals. One male treated with cortisol only had small palpable bulbourethral glands. Most of the individuals treated with cortisol only acquired an obese lower abdomen, which remained until the end of the experiment in some individuals. On dissection, this intra-abdominal material had a watery consistency, unlike subcutaneous fat present in males treated with saline or testosterone only. The two individuals treated with cortisol only which died before the end of the experiment had duodenal bleeding, blood in their urine and one individual was severely infested with nematodes in both the liver and gut.

In all males treated with testosterone plus cortisol the sternal gland was large and secretory. The scrotal sacs of all but one male were dark, losing fur and not fully retractile. All males treated with testosterone plus cortisol had a mature erectile penis, evident within 10 days of hormone injection. The bulbourethral glands were palpable within the same time and, by the end of the experiment, were moderate to large and were observed in some individuals as two masses, one on each side of the urogenital sinus. The individual that was killed before the end of the experiment had duodenal bleeding and blood in the urine.

\section{Body mass}

Administration of testosterone increased body mass (testosterone $P=0.01$, cortisol $P=0.087$, interaction $P=0.16$; Table 1).

\section{Testis}

Testes mass and scrotal width. The differences in scrotal width between before and after the hormone treatment were smaller in both groups treated with cortisol (testosterone NS, cortisol $P<0.05$, interaction not significant; Table 1 ). The testes mass did not differ between groups (testosterone not significant, cortisol not significant $(P=0.14)$, interaction not significant), or when expressed as a percentage of body mass (testosterone not significant, cortisol not significant, interaction not significant; Table 1).

Testicular morphology. All four groups showed similar seminiferous tubule morphology. All males had late spermatids and two males treated with testosterone only and one male treated with cortisol only also had mature spermatozoa in the seminiferous tubules. However, all individuals in all groups had maturing spermatozoa at various stages of spermiogenesis, and also developing spermatocytes lining the basement of the tubules.

The intertubular tissue of the testes of all individuals was plentiful and, in most individuals, was full of polyhedral Leydig cells. In most individuals from all groups, the Leydig cells were strongly eosinophilic. However, the interstitial tissues of the males treated with testosterone only were more variable than in other groups, with some individuals having hypertrophied cells that had proliferated throughout the enlarged intertubular space. Other individuals treated with testosterone only had interstitial tissue that was indistinguishable from the controls and, in some individuals, the interstitial material was reduced. This variability was not observed in individuals from other groups.

Epididymal morphology. The epididymides of males treated with saline or cortisol only were similar to those of the wild animals in May (McAllan et al., 1997a). The epithelial cells of the caput end were simple and columnar in appearance, and the epithelial cells of the caudal end were more columnar. However, there was considerable hypertrophy of the epididymal epithelia in both groups treated with testosterone, and the appearance was similar to that in wild reproductive males in August (McAllan et al., 1997a).

Epididymal morphometry. The caput epithelial cell height did not differ significantly between groups (testosterone not significant, cortisol not significant, interaction $P=0.17$; Table 2). Similarly, the caput epithelial cell volume did not differ 





Table 2. Measurements within the epididymides of male Antechinus stuartit treated with either saline, testosterone only, cortisol only or testosterone plus cortisol

\begin{tabular}{|c|c|c|c|c|}
\hline Treatment & $\begin{array}{l}\text { Caput } \\
\text { epithelial } \\
\text { height } \\
(\mu \mathrm{m})\end{array}$ & $\begin{array}{l}\text { Caput } \\
\text { epithelial } \\
\text { volume } \\
\left(\mu \mathrm{m}^{3}\right)\end{array}$ & $\begin{array}{l}\text { Caudal } \\
\text { epithelial } \\
\text { height } \\
(\mu \mathrm{m})\end{array}$ & $\begin{array}{l}\text { Caudal } \\
\text { epithelial } \\
\text { volume } \\
\left(\mu \mathrm{m}^{3}\right)\end{array}$ \\
\hline Saline $(n=6)$ & $15.7 \pm 1.0$ & $350.3 \pm 151.0$ & $27.0 \pm 1.3^{\mathrm{b}}$ & $1046.2 \pm 241.4^{b}$ \\
\hline Testosterone $(n=6)$ & $16.9 \pm 1.0$ & $789.5 \pm 193.2$ & $39.1 \pm 1.3^{a}$ & $1754.9 \pm 204.5^{\mathrm{a}}$ \\
\hline Cortisol $(n=6)$ & $16.2 \pm 1.7$ & $459.7 \pm 96.1$ & $27.9 \pm 1.0^{\mathrm{b}}$ & $697.3 \pm 49.8^{b}$ \\
\hline Testosterone + cortisol $(n=6)$ & $14.1 \pm 0.7$ & $466.0 \pm 61.3$ & $39.5 \pm 2.1^{\mathrm{a}}$ & $1735.2 \pm 130.5^{\mathrm{a}}$ \\
\hline Testosterone & NS & NS & $P<0.0001$ & $P<0.0002$ \\
\hline Cortisol & NS & NS & NS & NS \\
\hline Testosterone $\times$ cortisol & NS & NS & NS & NS \\
\hline
\end{tabular}

Data are means \pm SEM. Two-way ANOVA results are below values in each column.

Different letters in a column indicate that the values are significantly different from one another $(P<0.05)$.

significantly between groups (testosterone not significant $(P=0.14)$, cortisol not significant, interaction not significant $(P=0.15)$; Table 2). The caudal epithelial cell heights were increased significantly by the administration of testosterone (testosterone $P<0.0001$, cortisol not significant, interaction not significant; Table 2) as were the caudal cell epithelial volumes (testosterone $P<0.0002$, cortisol not significant, interaction not significant; Table 2).

\section{Accessory reproductive tract}

Prostate. The prostate mass changed significantly with the administration of testosterone and cortisol (testosterone $P<0.0001$, cortisol $P<0.0001$, interaction $P<0.0001$; Table 1). Testosterone significantly increased prostate mass but interacted with cortisol such that the prostate mass of males treated with testosterone plus cortisol was less than that of males treated with testosterone only, but greater than that of males treated with cortisol only or saline (Table 1). The same relationship was observed when prostate mass was expressed as a percentage of body mass (testosterone $P<0.0001$, cortisol $P<0.05$, interaction $P<0.002$; Table 1 ).

The prostate of males treated with saline had a translucent anterior portion and a more opaque posterior portion and were macroscopically similar to those observed in males in May in a previous study (McAllan et al, 1997a). The microscopic anatomy was also similar, with no differentiation of the secretory tubules along the length of the prostate (Fig. Ia). The same was also true of the prostate of males treated with cortisol only (Fig. Ib).

However, treatment with testosterone, either with or without cortisol, produced significant alterations in the morphology of the prostate (Fig. 2). The anterior portion was translucent, while the posterior portion was white and opaque. The internal segmentation was pronounced, with the anterior portion containing tubules of simple cuboidal epithelium with enlarged lumina full of secretory material (Fig. 2a, c). The secretory material of the anterior portion was PAS-positive, but the epithelium stained with neither PAS nor Alcian blue. The posterior portion had tubules that were aligned towards
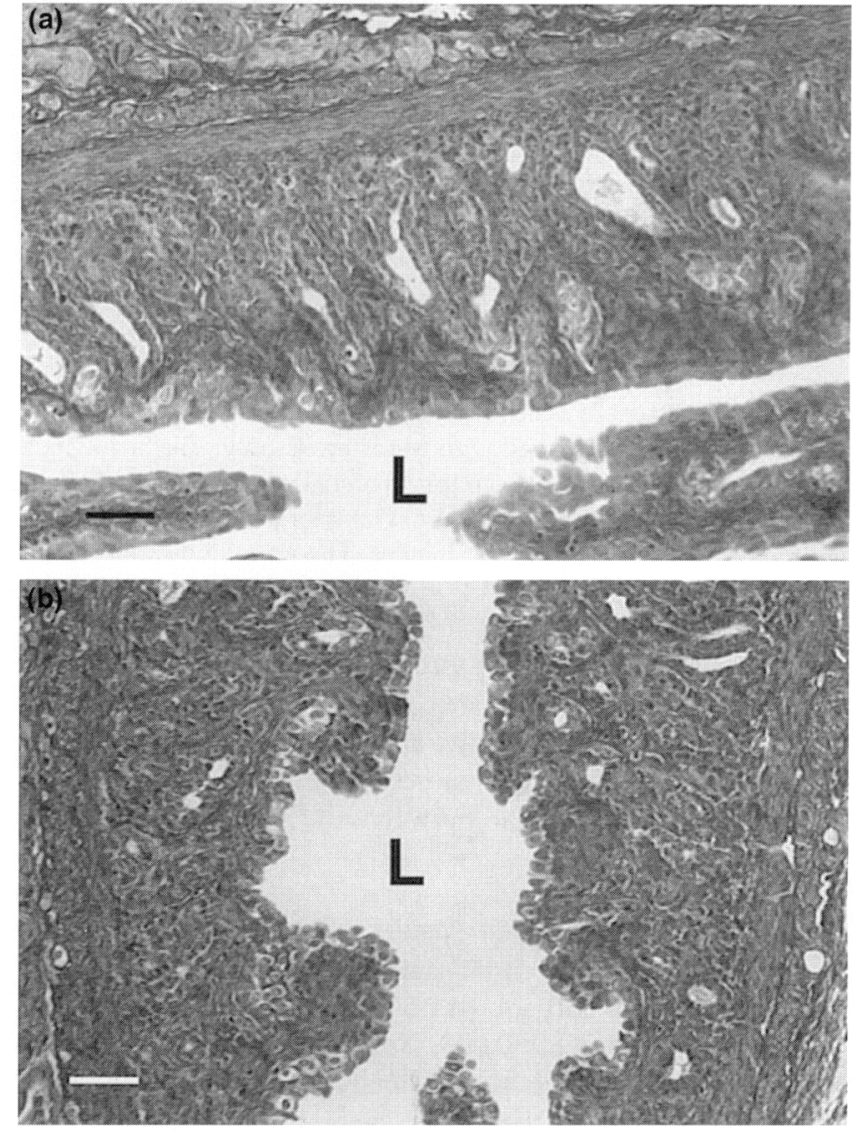

Fig. 1. The prostate of a male Antechinus stuartii treated with (a) saline only, and (b) cortisol only. Both the anterior and posterior segments of the prostate are shown. L: lumen of urethra. Scale bars represent $50 \mu \mathrm{m}$.

the urethral centre of the prostate and consisted of columnar epithelia that secreted material into small lumina (Fig. 2b, d). Staining with Masson's trichrome and PAS-Alcian blue provided differential staining of the tubular epithelium, similar to the seasonal study (McAllan et al., 1997a). 

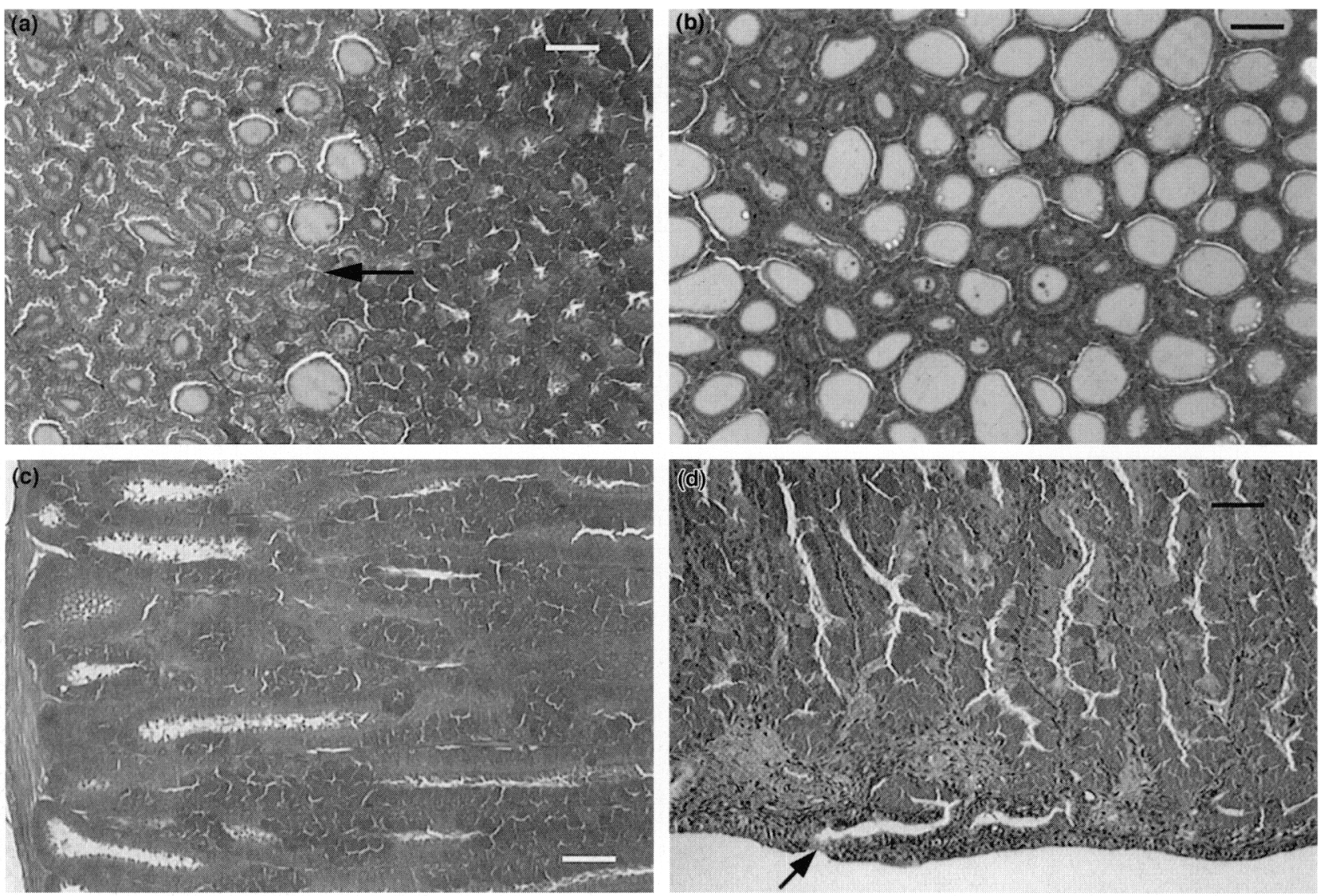

Fig. 2. Prostates of male Antechinus stuartii treated with testosterone. (a) Junction of the anterior (left) and posterior (right) portions of the prostate of a male treated with testosterone only. The arrow indicates the junction. (b) Posterior portion of the prostate of a male treated with testosterone only. Secretory material can be seen in the lumina of the tubules. (c) Anterior portion of the prostate of a male treated with testosterone plus cortisol. (d) Posterior portion of the prostate of a male treated with testosterone plus cortisol. Secretory material can be seen in the lumina of the tubules. The arrow indicates a secretory duct opening into the urethral lumen. Scale bars represent $50 \mu \mathrm{m}$.

The morphology of the prostates of males treated with testosterone plus cortisol was similar to that of the males treated with testosterone only, although the hypertrophy was often not as obvious. The morphological differentiation and staining were also similar between the testosterone treated groups (Fig. 2c, d).

Cowper's or bulbourethral glands. The mass of the bulbourethral gland changed significantly with the administration of testosterone and cortisol (testosterone $P<0.0001$, cortisol $P<0.01$, interaction $P<0.005$; Table 1). Testosterone significantly increased bulbourethral gland mass, but interacted with cortisol such that the bulbourethral gland mass of males treated with testosterone plus cortisol was less than that of males treated with testosterone only, but greater than that of males treated with saline or cortisol only (Table 1). A similar relationship was observed when bulbourethral gland mass was adjusted for body mass (testosterone $P<0.0001$, cortisol not significant $(P=0.11)$, interaction $P<0.02$; Table 1).

The macroscopic morphology of the bulbourethral glands was similar in the males treated with saline and in males treated with cortisol only. Gland IV (Fig. 3c, f) was the only one that was easily identified; however, histologically there was some differentiation of the other bulbular structures (Fig. 3a, b, d, e). Glands I, II, and III were small associations of tubules with simple cuboidal epithelium. At this point (early June) they were discrete units, but had no internal secretory specializations (Fig. 3a, b, d,e). The urethral bulbs were small and indistinguishable from those of wild males in May.

The bulbourethral glands of the males treated with testosterone only were both macroscopically and histologically hypertrophied (Fig. 4). All bulbourethral glands were easily identified on dissection and gland III, in particular, was considerably enlarged. The muscular layers of the urethral bulb had increased in size. The secretory differentiation seen in wild males from July and August (McAllan et al, 1997a) was again observed in glands I, II and III. In glands I and II the simple columnar epithelia lined tubules the lumina of which were extensively expanded by secretory material (Fig. 4a,b). The secretory material in gland I was PAS-positive and did not stain with Alcian blue, stained bright red with Masson's trichrome and was colloidal-like in appearance (Fig. 4b). In gland II, the crystalline material observed in wild males was again present, and stained red and blue with Masson's trichrome and was PAS-positive and Alcian blue-negative (Fig. 4b). Gland III consisted of branching tubules that drained into common ducts leading to the urethral opening (Fig. 4c). 

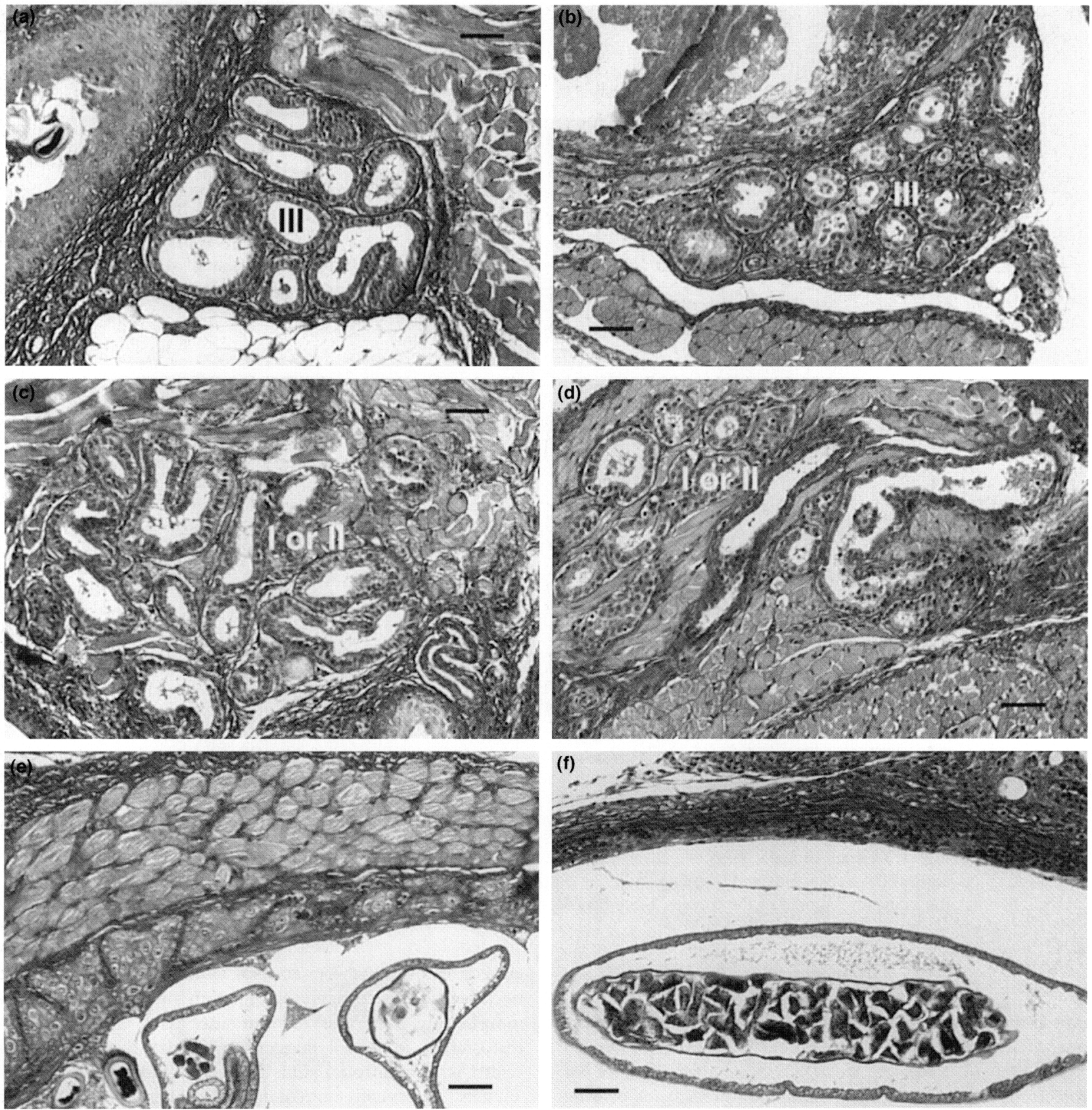

Fig. 3. The bulbourethral glands of male Antechinus stuartii treated with saline only $(a, c, e)$ and with cortisol only (b, d, f). (a, b) Bulbourethral gland III (III) with associated skeletal muscle (upper right). To the upper left is part of gland IV. (c, d) Bulbourethral gland I or II (I or II) with associated skeletal muscle (upper right). It was not possible to distinguish between glands I and II. (e, f) Bulbourethral gland IV demonstrating luminal lining, and skeletal muscle capsule. (e) Parasites and their eggs and (f) a large parasite are easily observed in the lumen. Scale bars represent $50 \mu \mathrm{m}$.

The secretory cuboidal epithelium of the tubules of gland III stained weakly with PAS and the luminal surface stained with Alcian blue pH 1.0 and 2.5. The secretory material in the lumina of the tubules was PAS-positive. Gland IV had a similar structure to those of males treated with saline or cortisol only, although the layers of striated muscle and the transitional epithelium lining the gland were enlarged.

The bulbourethral glands of the males treated with testosterone plus cortisol were also easily distinguished macroscopi- cally. Their histological appearance was very similar to that of the males treated with testosterone only (Fig. $4 \mathrm{~d}-\mathrm{f}$ ). However, there were some differences. While the cytostructure of all glands was similar to that of the males treated with testosterone only, there was often less secretory material located in the lumina of the tubules. The staining affinities were the same as for the males treated with testosterone only. Gland IV was similar in structure to that of males treated with testosterone only. 

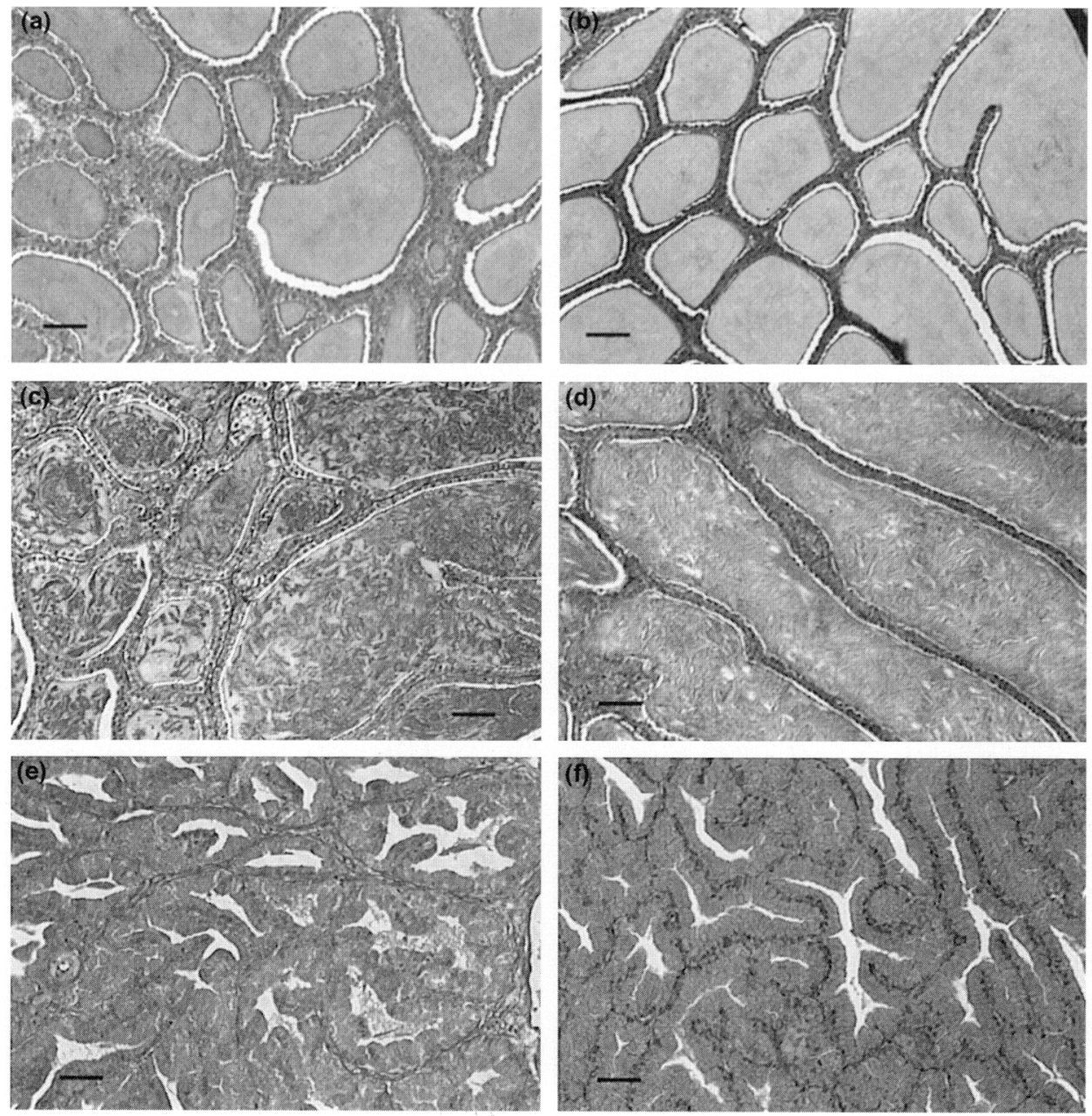

Fig. 4. Prostate of male Antechinus stuartii treated with testosterone only ( $a, c, e)$ and testosterone plus cortisol (b, d, f). (a, b) Gland I; (c, d) gland II; (e, f) gland III. Gland III has some secretory material within the branching lumina of the tubules. Scale bars represent $50 \mu \mathrm{m}$.

\section{Discussion}

The present study demonstrates that administration of testosterone and cortisol significantly alters the accessory reproductive tract of male $A$. stuartii. Under the influence of testosterone, the prostate and the bulbourethral glands became differentiated and hypertrophied, and the lumina were full of secretory material. The addition of cortisol to the testosterone diminished the response to testosterone. However, some parts of the reproductive tract, notably the seminiferous tubules, remained unaltered by hormone administration. The epididymis was segmentally sensitive to the effects of testosterone, with only the caudal end responding to hormone administration.

These findings confirm many hypotheses concerning reproductive activity in male $A$. stuartii, especially that of the independence of the spermatogenic cycle from the androgen cycle, and the dependence of the accessory reproductive tract on the presence of androgens (Bradley et al., 1980; McAllan et al., 1997a). The accessory glands were sensitive to the presence of testosterone and, in general, the testes were not responsive. Testicular mass did not change with treatment of either testosterone or cortisol, although testicular width decreased with cortisol treatment. Moreover, the testicular morphology and mass did not alter with either cortisol or testosterone treatment, suggesting that the decrease in scrotal width is extragonadal. On dissection, the scrotal tissues of animals treated with cortisol did not contain as much surrounding fat and retractor muscles as those of animals not treated with cortisol. The external appearance was also more degenerated in many of the males treated with cortisol than in males treated with either saline or testosterone. Some of the metabolic actions of cortisol include hepatic gluconeogenesis, hyperglucagonaemia and centripetal obesity (Tepperman and Tepperman, 1987). These widespread effects of cortisol observed in the general appearance of treated males may also affect the scrotal tissue surrounding the testes, thus diminishing scrotal width in males treated with cortisol.

The similar testicular mass and morphology among all males, and their insensitivity to hormone treatment, concur with some other studies on marsupials, and differs from some studies on eutherian mammals. In some eutherian mammals, testicular mass and morphology often correspond positively to plasma testosterone concentrations (Zaime et al., 1992). However, 
in marsupials, this is not always the case. Androgen concentrations are not correlated with testicular size in many marsupials (Phascolarctos cinereus, Cleva et al., 1994; Macropus eugenii, Inns, 1982; Didelphis albiventris, de Queiroz et al., 1995; A. minimus, Wilson and Bourne, 1984; A. stuartii, Kerr and Hedger, 1983) but do correlate with scrotal width in eastern quolls (Dasyurus viverrinus, Bryant, 1986). Moreover, the spermatogenic activity of many marsupials is not associated with seasonal androgen cycles (Inns, 1982; Kerr and Hedger, 1983; Wilson and Bourne, 1984; Curlewis, 1991).

The present study confirms that spermatogenic activity and peak androgen concentrations are independent in $A$. stuartii, as seen in many marsupials. Testosterone administration had no effect on the spermatogenesis of $A$. stuartii, even though it is believed to be essential for promoting spermatogenesis and for early germ cell development and later spermiogenesis in other mammals (McLachlan et al., 1996). However, low testicular concentrations of testosterone may be tenfold higher than peripheral concentrations and still be sufficient to maintain testicular activity (Rommerts, 1988). The testicular lymph of rats can have 15-35 times higher concentrations of testosterone than the venous drainage, and the concentration gradients are higher from the Leydig cells to the peripheral circulation (Rommerts, 1988). It is thus possible that spermatogenic activity in marsupials, and especially in $A$. stuartii, may be regulated locally by the mature Leydig cells.

This contrasts with the epididymides and accessory reproductive tract of marsupials, which rely on significantly higher concentrations of plasma testosterone to maintain cellular activity. In $A$. stuartii, the epididymis was differentially sensitive to testosterone administration. The caput end of the epididymis did not significantly change in epithelial height or volume, although the values for this time of year (early June) were intermediate between the May and July values (McAllan et al., 1997a). Taggart et al. (1993) suggested that the epithelial cells of the caput epididymis are more sensitive to androgen concentrations than are the cells of the caudal regions. This hypothesis was based on the early development of the epididymis, in which the anterior end develops earlier, in association with greater blood supply to the anterior end, and delivers more androgens to this end of the epididymis (Taggart et al., 1993). However, the present study suggests that in adult $A$. stuartii the caput end of the epididymis is less sensitive to testosterone administration than the caudal end, where significant increases in epithelial cell height and volume were directly related to testosterone administration. This may be related to sperm storage. Previous studies suggest that the morphology of the caudal end makes sperm storage unlikely in males, although it may serve to limit the number of spermatozoa released on ejaculation, to maximize the number of successful matings (Taggart and Temple-Smith, 1989, 1990; Taggart et al., 1993). The results of the present study suggest that the development of the caudal end is under control of testosterone in preparation for sperm release during the mating period.

In other marsupials, the epididymal mass can change seasonally, although the response to testosterone is less clear. There is a small seasonal increase during the breeding season in the mass of epididymides of the brushtail possum, $T$. vulpecula (Curlewis and Stone, 1985), whereas no seasonal change in epididymal mass has been observed in other marsupial species (Inns, 1982; Curlewis, 1991; de Queiroz et al., 1995). However, epididymal segmental differences in sensitivity to androgen administration and also in $5 \alpha$-reductase activity occur in Macropus eugenii (Jones et al., 1988).

The conversion of testosterone to dihydrotestosterone (DHT) by $5 \alpha$-reductase is believed to be an important mechanism of testosterone activity in the reproductive tract of mammals and, in the prostate, absence of $5 \alpha$-reductase causes cell death (Rittmaster $e t$ al., 1995). High activity of $5 \alpha$-reductase has been reported in the epididymides of marsupials (Cook et al., 1978; Curlewis and Stone, 1985; Jones et al., 1988) and, in the tammar ( $M$. eugenii), this is not associated with sensitivity to testosterone. Paradoxically, there is much evidence to suggest that the prostate is far more sensitive to the actions of testosterone, even though there is less $5 \alpha$-reductase and little conversion of testosterone to DHT (Cook et al., 1978; Curlewis and Stone, 1985; Jones et al., 1988). This has perplexed some authors and there is some agreement that the prostate may be supported by androgens transported along the excurrent ducts of the testes into the urethra (Cook et al., 1978; Temple-Smith, 1984). However, in hamsters, the testes are the main source of circulating DHT, and conversion of testosterone to DHT in peripheral organs appears to be negligible (Lerchl and Nieschlag, 1995). It is possible that DHT is converted from testosterone by $5 \alpha$-reductase in the epididymides of marsupials and then transported to the accessory reproductive tract by the excurrent ducts or venous drainage.

However, testosterone administration to castrated tammars caused an overshoot in the mass of Cowper's glands and prostate compared with intact males (Jones et al., 1988). The mass of the epididymis of castrated males did not return to intact values with testosterone administration, although the epithelial heights of the caudal end were closer to values for intact males (Jones et al., 1988). The greater sensitivity to testosterone of the caudal end of the epididymis in $A$. stuartii was also evident in the present study, as was the pronounced sensitivity of the prostate and Cowper's glands to testosterone administration.

Prostate mass and activity show close association with testosterone concentration in other marsupials (Cook et al., 1978; Inns, 1982; Wilson and Bourne, 1984), and in A. stuartii (Bradley et al., 1980). The present study supports this but, unlike previous studies, also includes the effect of cortisol on the reproductive tract. Similar to testosterone, cortisol administration did not affect the seminiferous tubules. However, in contrast to testosterone, administration of cortisol alone had no significant effect on the caudal epididymis, the prostate or the bulbourethral glands. Addition of cortisol to testosterone administration caused a significant negative interaction between the two hormones, such that cortisol diminished the hypertrophic effects of testosterone. The reduced effect of the combination of the two hormones produced significant correlations with seasonal changes in wild males (McAllan et al., 1997a). This was true of both the body mass and the accessory reproductive tract mass. The masses of both the bulbourethral glands and the prostate of animals treated with testosterone plus cortisol were similar to those found by Woolley (1966) and Bradley et al. (1980) for animals during the breeding season. The masses of both the bulbourethral glands and the 
prostate of animals treated with testosterone only were greater than normal, and this finding is similar to that reported by Jones et al. (1988) for the tammar.

The morphology of the accessory glands reflected the changes in mass. Both the bulbourethral glands and the prostate of males treated with testosterone only had considerably more secretory material in the lumina of the tubules than the males treated with testosterone plus cortisol. The content and appearance of the prostate and the bulbourethral glands of males treated with testosterone plus cortisol are similar to those seen in males from August in the seasonal study (McAllan et al., 1997a).

Cortisol appears to reduce the effect of testosterone on the secretory activity of the cells produced by testosterone. Studies on male mammals have found that seminal vesicle and prostate masses are inversely related to adrenal activity (Christian, 1955; Andrews et al. 1972). Administration of adrenocorticotrophic hormone stimulates adrenal activity and arrests testicular development in some rodents (Pasley and Christian, 1971; Monder et al., 1994). These findings differ from the present study, in which cortisol administration did not affect testicular activity.

Glucocorticoids have been found to halve the plasma concentration of testosterone in men without changing steroidbinding globulin capacity and, in baboons, the testicular response to $\mathrm{LH}$ is attenuated by high circulating concentrations of cortisol (Sapolsky, 1985; Loriaux and Nieman, 1990). The present study demonstrated that cortisol affected the accessory reproductive tract but did not disrupt testicular activity or alter the morphology of the prostate and bulbourethral glands. Administration of cortisol only caused a small but significant increase in prostate and bulbourethral mass, indicating some interaction between corticosteroids and androgen actions. However, the main effect of cortisol administration observed in the present study was to negate the hypertrophic stimulation of the accessory reproductive tract by testosterone administration.

In conclusion, it can be seen that testosterone and cortisol affect the reproductive tract of $A$. stuartii. The seminiferous tubules are insensitive to hormone action but the further the target organs are from the site of testosterone production, the greater the sensitivity to the actions of the hormone. This pattern of hormone sensitivity is similar to that of other marsupials. Moreover, the morphology and morphometric changes observed in male $A$. stuartii treated with testosterone plus cortisol mimic those seen in wild males at the time of reproduction in August.

The study was supported by an Australian Postgraduate Award, and by a grant from the Australian Research Council to B. M. McAllan. The author would like to thank J. R. Roberts, T. O'Shea, and F. Geiser for critically reading the manuscript, and T. Geiser, F. Geiser and G. Körtner for help in the field.

\section{References}

Andrews RV, Belknap RW, Southard J, Lorincz M and Hess S (1972) Physiological, demographic and pathological changes in wild Norway rat populations over an annual cycle Comparative and Biochemical Physiology 41A $149-165$

Bradley AJ, McDonald IR and Lee AK (1975) Effect of exogenous cortisol on mortality of a dasyurid marsupial Journal of Endocrinology 66 281-282
Bradley AJ, McDonald IR and Lee AK (1980) Stress and mortality in a small marsupial (Antechinus stuartii, Macleay) General and Comparative Endocrinology 40 188-200

Bryant SL (1986) Seasonal variation of plasma testosterone in a wild population of male eastern quoll, Dasyurus viverrinus (Marsupialia: Dasyuridae) General and Comparative Endocrinology $6475-79$

Christian JJ (1955) Effects of population size on the adrenal glands and the reproductive organs of male mice in populations of fixed size American Journal of Physiology 182 292-300

Cleva GM, Stone GM and Dickens RK (1994) Variation in reproductive parameters in the captive male koala (Phascolarctos cinereus) Reproduction, Fertility and Development 6 713-719

Cook B, McDonald IR and Gibson WR (1978) Prostatic function in the brush-tailed possum, Trichosurus vulpecula. Journal of Reproduction and Fertility 53 369-375

Curlewis JD (1991) Seasonal changes in the reproductive organs and plasma and pituitary hormone content of the male Bennett's wallaby (Macropus rufogriseus rufogriseus) Journal of Zoology (London) 223 223-231

Curlewis JD and Stone GM (1985) Some effects of breeding season and castration on the prostate and epididymis of the brushtail possum, Trichosurus vulpecula. Australian Journal of Biological Sciences 38 313-326

de Queiroz GF, Rosa AAM, Ailva E and Nogueira JC (1995) Testicular sperm reserve and plasma testosterone levels of the South American white-belly opossum (Didelphis albiventris), Marsupialia Mammalia 59 255-261

Drury RAB and Wallington EA (1980) Carleton's Histological Technique 5th Edn p. 520 Oxford University Press, Oxford

Gemmell RT, Cepon G and Barnes A (1986) Weekly variations in body weight and plasma testosterone concentrations in the captive male possum. Trichosurus vulpecula. General and Comparative Endocrinology 62 1-7

Gundersen HJG, Bagger P, Bendtsen TF, Evans SM, Korbo L, Marcussen N, Møller A, Nielsen K, Nyengaard JR, Pakkenberg B, Sorensen FB, Vesterby A and West MJ (1988a) The new stereological tools: disector, fractionator, nucleator and point sampled intercepts and their use in pathological research and diagnosis Acta Pathologica Microbiologica Immunology Scandinavia 96 857-881

Gundersen HJG, Bendtsen TF, Korbo L, Marcussen N, Moller A, Nielsen K, Nyengaard JR, Pakkenberg B, Sorensen FB, Vesterby A and West MJ (1988b) Some simple and efficient stereological methods and their use in pathological research and diagnosis Acta Pathologica Microbiologica Immunology Scandinavia 96 379-394

Haycock KA, Roth J, Gagnon J, Finzer WF and Soper C (1992) Statview "i p. 466 Abacus Concepts Incorporated, Berkeley, CA

Inns RW (1982) Seasonal changes in the accessory reproductive system and plasma testosterone levels of the male tammar wallaby, Macropus eugenii, in the wild Journal of Reproduction and Fertility 66 675-680

Jones RC, Stone GM, Hinds LA and Setchell BP (1988) Distribution of $5 \alpha$-reductase in the epididymis of the tammar wallaby (Macropus eugenii) and dependence of the epididymis on systemic testosterone and luminal fluids from the testis Journal of Reproduction and Fertility $83779-783$

Kerr JB and Hedger MP (1983) Spontaneous spermatogenic failure in the marsupial mouse Antechinus stuartii, Macleay (Dasyuridae: Marsupialia) Australian Journal of Zoology $31445-466$

Lerchl A and Nieschlag E (1995) Diurnal variations of serum and testicular testosterone and dihydrotestosterone (DHT) in Djungarian hamsters (Phodopus sungorus): testes are the main source for circulating DHT General and Comparative Endocrinology 98 129-136

Loriaux L and Nieman L (1990) Stress and reproduction: the role of cortisol. In Neuroendocrine Regulation of Reproduction pp 307-311 Eds SSC Yen and WW Vale. Serono Symposia USA, Norwell, MA

McAllan BM, Joss JMP and Firth BT (1991) Phase delay of the natural photoperiod alters reproductive timing in the marsupial Antechinus stuartii. Journal of Zoology (London) $225633-646$

McAllan BM, Roberts JR and O'Shea T (1997a) Seasonal changes in the reproductive anatomy of male Antechinus stuartii (Marsupialia: Dasyuridae) Journal of Morphology 231 261-275

McAllan BM, Roberts JR and O'Shea T (1997b) Effects of testosterone and cortisol on the renal morphology of male Antechinus stuartii (Marsupialia) General and Comparative Endocrinology 107, 439-449

McDonald IR, Lee AK, Bradley AJ and Than KA (1981) Endocrine changes in dasyurid marsupials with differing mortality patterns General and Comparative Endocrinology 44 292-30I

McLachlan RI, Wredford NG, O'Donnell $L$, de Kretser DM and Robertson DM (1996) The endocrine regulation of spermatogenesis: independent roles for testosterone and FSH Joumal of Endocrinology 148 1-9 
Monder C, Miroff Y, Marandici A and Hardy MP (1994) 11ß-hydroxysteroid dehydrogenase alleviates glucocorticoid mediated inhibition of steroidogenesis in rat Leydig cells Endocrinology 134 1199-1204

Moore GH (1974) Aetiology of the Die-off of Male Antechinus stuartii. PhD Thesis, Australian National University, Canberra p. 125

Pasley JN and Christian JJ (1971) Effects of ACTH on voles (Microtus pennsylvanicus) related to reproductive function and renal disease Proceedings of the Society for Experimental Biology and Medicine 137 268-272

Rittmaster RS, Manning AP, Wright AS, Thomas LN, Whitefield S, Norman RW, Lazier CB and Rowden G (1995) Evidence for atrophy and apoptosis in the ventral prostate of rats given the $5 \alpha$-reductase inhibitor finasteride Endocrinology $136741-748$

Rommerts FFG (1988) How much androgen is required for maintenance of spermatogenesis? Journal of Endocrinology 116 7-9

Sapolsky RM (1985) Stress-induced suppression of testicular function in the wild baboon: role of glucocorticoids Endocrinology 116 2273-2278

Taggart DA and Temple-Smith PD (1989) Structural features of the epididymis in a dasyurid marsupial (Antechinus stuartii) Cell and Tissue Research 258 203-210

Taggart DA and Temple-Smith PD (1990) The effects of breeding season and mating on total number and relative distribution of spermatozoa in the epididymis of the brown marsupial mouse, Antechinus stuartii. Journal of Reproduction and Fertility $\mathbf{8 8} 81-91$
Taggart DA and Temple-Smith PD (1992) Postnatal development of the ductus epididymis in a dasyurid marsupial (Antechinus stuartii) Anatomy and Embryology $186 \quad 259-270$

Taggart DA, Johnson J and Temple-Smith PD (1993) Testicular and epididymal development in the brown marsupial mouse, Antechinus stuartii (Dasyuridae, Marsupialia) Anatomy and Embryology 188 87-100

Temple-Smith PD (1984) Reproductive structures and strategies in male possums and gliders. In Possums and Gliders pp 89-106 Eds AP Smith and ID Hume. Australian Mammal Society, Sydney

Tepperman J and Tepperman HM (1987) Metabolic and Endocrine Physiology 5th Edn p. 369 Year Book Medical Publishers, Chicago

Wilson BA and Bourne AR (1984) Reproduction in the male dasyurid Antechinus minimus maritimus (Marsupialia: Dasyuridae) Australian Journal of Zoology 32 $311-318$

Woolley P (1966) Reproduction in Antechinus spp and other dasyurid marsupials Symposia of the Zoological Society of London 15 281-294

Zaime A, Laraki M, Gautier J-Y and Garnier DH (1992) Seasonal variations of androgens and of several sexual parameters in male Meriones shawi in southern Morocco General and Comparative Endocrinology 86 289-296

Zar JH (1984) Biostatistical Analysis 2nd Edn p. 718 Prentice Hall, London 